\title{
Pulmonary epithelioid haemangioendothelioma in 21 patients, including three with partial spontaneous regression
}

\author{
M. Kitaichi*, S. Nagai**, K. Nishimura**, H. Itoh+, H. Asamoto", T. Izumi**, D.H. Dail\#
}

Pulmonary epithelioid haemangioendothelioma in 21 patients, including three with partial spontaneous regression. M. Kitaichi, S. Nagai, K. Nishimura, H. Itoh, H. Asamoto, T. Izumi, D.H. Dail. @ ERS Journals Ltd 1998.

ABSTRACT: This investigation studied the general conditions and prognostic factors of pulmonary epithelioid haemangioendothelioma (PEH), which is a rare disease.

Twenty-one patients were collected throughout Asia by a questionnaire.

Age at the detection or onset of symptoms of PEH was 14-64 yrs (mean 44 yrs). Males were more likely to be detected by symptoms $(4 / 8,50 \%)$ than were females $(1 /$ 13, 8\%). Fifteen showed bilateral multiple nodular opacities. Partial spontaneous regression occurred in three asymptomatic patients (one male and two females, all with bilateral multiple nodular opacities) 5,13 and 15 yrs after detection. Two of the three patients with pleural effusion died within $1 \mathrm{yr}$, while the 16 patients with no effusion were alive more than $1 \mathrm{yr}$ later $(\mathbf{p}<0.05)$. Histologically, two patients with fibrinofibrous pleuritis and extrapleural proliferation of tumour cells died within 2 yrs, while only one of 14 patients lacking such manifestations died within the same period $(p<0.05)$. All three patients without spindle tumour cells survived for $12 \mathrm{yrs}$ after the diagnosis, while all four patients with such cells died during the same period $(\mathbf{p}<\mathbf{0 . 0 5})$.

In conclusion, 21 patients with pulmonary epithelioid haemangioendothelioma were reported, of whom three demonstrated partial spontaneous regression, and adverse prognostic features were identified.

Eur Respir J 1998; 12: 89-96.

Pulmonary epithelioid haemangioendothelioma (PEH) is a rare tumour of the lung. The disease was originally reported by DAlL and LIEBOW [1] in 1975 as "intravascular bronchoalveolar tumour" (IVBAT), and the majority $(65 \%)$ patients of the reported 20 patients showed multiple bilateral nodular lesions. In addition, one patient had bronchoalveolar cell carcinoma. The recognition of Weibel-Palade bodies in the cytoplasm of tumour cells of IVBAT by electron microscopy, along with the immunoreactivity of the cytoplasm of tumour cells for factor VIII-related antigen, prompted the realization that IVBAT probably derived from vascular endothelial cells [2-9]. Forty-one patients with soft-tissue neoplasms exhibiting histopathological features similar to IVBAT were reported by WeISS and ENZINGER [10] in 1982. The tumour was termed epithelioid haemangioendothelioma [2, 9-12], and by 1986 had been reported to occur also in the liver, head and neck area, oral mucosa, bone, mediastinum, diaphragm and brain [13].

We reported on two asymptomatic patients with IVBAT (PEH) in the mid-1980s [14, 15], and observed partial spontaneous regression of the disease during follow-up in both. In order to evaluate more thoroughly the clinicopathological spectrum of $\mathrm{PEH}, 21$ patients with $\mathrm{PEH}$ recruited in Asia (Japan, Korea, Taiwan and Singapore) were studied, who included an additional patient with partial spontaneous regression [16]. The description of all of these patients and their prognostic features form the basis of the present report.
*Laboratory of Anatomic Pathology and +Dept of Radiology, Kyoto University Hospital, Japan. **Dept of Respiratory Medicine, Graduate School of Medicine, Kyoto University, Japan. \#Dept of Respiratory Medicine, National Kyoto Hospital, Kyoto, Japan. \#Dept of Pathology, The Virginia Mason Clinic, Seattle, USA.

Correspondence: M. Kitaichi

Laboratory of Anatomic Pathology

Kyoto University Hospital

54 Shogoin Kawahora-cho

Sakyo-ku

Kyoto, 606-8507

Japan

Fax: 81757513499

Keywords: Intravascular bronchoalveolar tumour, prognosis, prognostic factors, pulmonary epithelioid haemangioendothelioma

Received: September 41997

Accepted after revision March 91998

\section{Methods}

\section{Study population}

To obtain data on the clinical and pathological features of PEH in as many patients as possible, a survey was carried out of the Japanese literature of the past $15 \mathrm{yrs}$ and letters were sent to Departments of Medicine, Respiratory Medicine, Radiology and Pathology of 230 major hospitals in Japan. In addition, letters were sent to five major hospitals in Korea, Taiwan, Hong Kong and Singapore. In order to confirm the diagnosis of $\mathrm{PEH}$, the histopathological specimens from 23 patients were reviewed at an International Meeting on PEH held in 1994 in Kyoto, Japan. Six out of the 23 patients have been reviewed previously by one of the present authors (M. Kitaichi) [14-17].

The clinical summary of patients with PEH focused on the features described in the Results section at the time of the first examination by their primary physicians (see Acknowledgements) and at the time of the last clinical contact.

The patients were also questioned about the type and duration of therapy, if any. The clinical onset of PEH was defined as the time of onset of pulmonary symptoms attributable to the disease. Clinical improvement or deterioration was assessed by chest radiography.

\section{Histopathological and immunohistochemical studies}

Histopathological features were analysed according to 18 items $[2,9]$. The cellularity of tumour cells was graded from 
1 to 3 , with 3 being the most compact cellular distribution. The presence of spindle cells was scored from 0 (absent) to 3 (marked), as described in the article by WeIsS and ENZINGER [10] for a model of grade 3 . Nuclear polymorphism of tumour cells was categorized as mild, moderate or severe. Tumour necrosis was categorized as grade 0 (none), 1 (minimal), $2(<25 \%), 3(25-50 \%), 4(50-75 \%)$ or 5 $(>75 \%)$.

Factor VIII-related antigen, an endothelial cell marker [18], was evidenced by the streptavidin-biotin complex (SBC) method, after predigestion with trypsin for $30 \mathrm{~min}$ [19]. Antibody for factor VIII-related antigen and reagents for streptavidin-biotin-peroxidase were purchased from Dako Japan (Kyoto, Japan) and from Nichirei \& Co. (Tokyo, Japan), respectively.

\section{Statistical analysis}

Data are expressed as mean \pm SD. Survival rate was analysed by the generalized Wilcoxon's test [20]. To compare the distribution of continuous variables in two groups, the Student's two-tailed t-test for nonpaired variables was used if the data were normally distributed, and Wilcoxon's rank sum test was used if they were not. Categorical variables were analysed by the Chi-squared test or Fisher's exact test. A p-value $<0.05$ was considered significant.

\section{Results}

\section{Pathological diagnosis}

Twenty one patients were diagnosed as having PEH after histopathological study of their lung specimens (table 1). Two patients were excluded from the study: one was diagnosed as having angiotropic lymphoma and the other highgrade epithelioid vascular tumour of lung. Ten of the 21 patients have been reported on previously [14-17, 21-26]. Histological findings of lung specimens fell within the PEH diagnosis guidelines, as described in previous reports [19, 11-13]. The endothelial origin of the tumour cells was confirmed immunohistochemically by using an antibody against factor VIII-related antigen in 15 of the 21 patients.

\section{Clinical features}

The 21 patients with PEH consisted of eight males and 13 females (table 1). There were 18 Japanese patients, one Korean, one Taiwanese and one Chinese patient. No specific occupational context was detected in any of the patients. Male patients with PEH tended to be detected more frequently by subjective symptoms $(4 / 8,50 \%)$ than did females $(1 / 13,8 \%)(p=0.06)$ (table 1). Fifteen patients were detected by chest radiograph during health examinations. One female patient was detected incidentally during systematic examination before surgery for meningioma.

Clinical and laboratory findings of the $21 \mathrm{PEH}$ patients, along with findings of the chest computed tomography (CT) scans in 18 patients at first examination are summarized in tables 2 and 3 . One male patient was found to have small, multiple, bilateral nodular opacities on chest CT, although only a single large nodular opacity of the right lung was noted on the chest radiograph [26].
Table 1. - Clinical findings in 21 patients with pulmonary epithelioid haemangioendothelioma (PEH) at the detection of the disease by chest radiography or at the onset of symptoms, and the diagnostic method

\begin{tabular}{lccc}
\hline & \multicolumn{3}{c}{ Number of patients } \\
\cline { 2 - 4 } & Total & Males & Females \\
& 21 & $8(38 \%)$ & $13(62 \%)$ \\
\hline Age at detection/onset yrs & $14-69$ & $14-69$ & $15-62$ \\
Mean yrs & 42.7 & 42.3 & 42.8 \\
(SD) & $(16.3)$ & $(20.9)$ & $(13.7)$
\end{tabular}

Incidence by decade yrs

11-20

21-30

$31-40$

41-50

51-60

61-70

PEH detected by chest radiography

PEH detected by symptoms*+ Dyspnoea

Cough

Sputum

Chest pain

Methods of pathological

diagnosis

Open lung biopsy

Partial lung resection

Lung surgery\#

Transbronchial lung biopsy§

Autopsy

$\quad(20.9)$

(13.7)

*: more male patients with PEH tended to be detected by subjective symptoms $(4 / 8,50 \%)$ compared with female patients (1/ $13,8 \%)(\mathrm{p}=0.06) .+$ : one male patient had chest pain, cough and sputum at the time of onset. unilateral partial lung resection $(\mathrm{n}=1)$; bilateral partial lung resection $(\mathrm{n}=1)$. \#: lobectomy $(\mathrm{n}=4)$; bilobectomy $(n=1)$; pleuropneumonectomy $(n=1)$. : diagnosis of transbronchial lung biopsy was confirmed by post mortem examination of lung tissues.

\section{Overall prognosis}

Among the 21 patients with $\mathrm{PEH}, 16$ patients are alive at the time of writing, and five have died in the meantime. 1) Three patients are alive without disease after lobectomy (follow-up period after lobectomy for a solitary lung tumour was 37-53 months (mean 44 months)). 2) Thirteen patients are alive with $\mathrm{PEH}$. The follow-up period after pathological diagnosis (11 patients with open lung biopsy, one patient with lobectomy and one with bilateral partial resection) was 1-320 months (mean 73 months). Of the 13, twelve patients had bilateral nodular opacities of PEH radiographically. One patient with a few unilateral pulmonary nodules underwent lobectomy. Three patients had antineoplastic chemotherapy, showing no effects. Nine patients were followed without specific treatment. Follow-up chest radiography showed no change in four, worsening in two and partial regression in three patients. 3) Four patients died of PEH [17, 22, 26]. All 4 patients had bilateral nodular opacities of PEH radiographically. Follow-up period of three patients after pathological diagnosis (transbronchial lung biopsy, pulmonary wedge resection and bi-lobectomy respectively) was 16-140 months (mean 59 months). The pathological diagnosis of the other patients was made by an autopsy [17]. 4) One male patient died of unknown causes 7 months after left pleuropneumonectomy for unilateral pleural effusion. The patient had ineffective antineoplastic chemotherapy after surgery. 
Table 2. - Clinical and laboratory findings in 21 patients with pulmonary epithelioid haemangioendothelioma at first examination

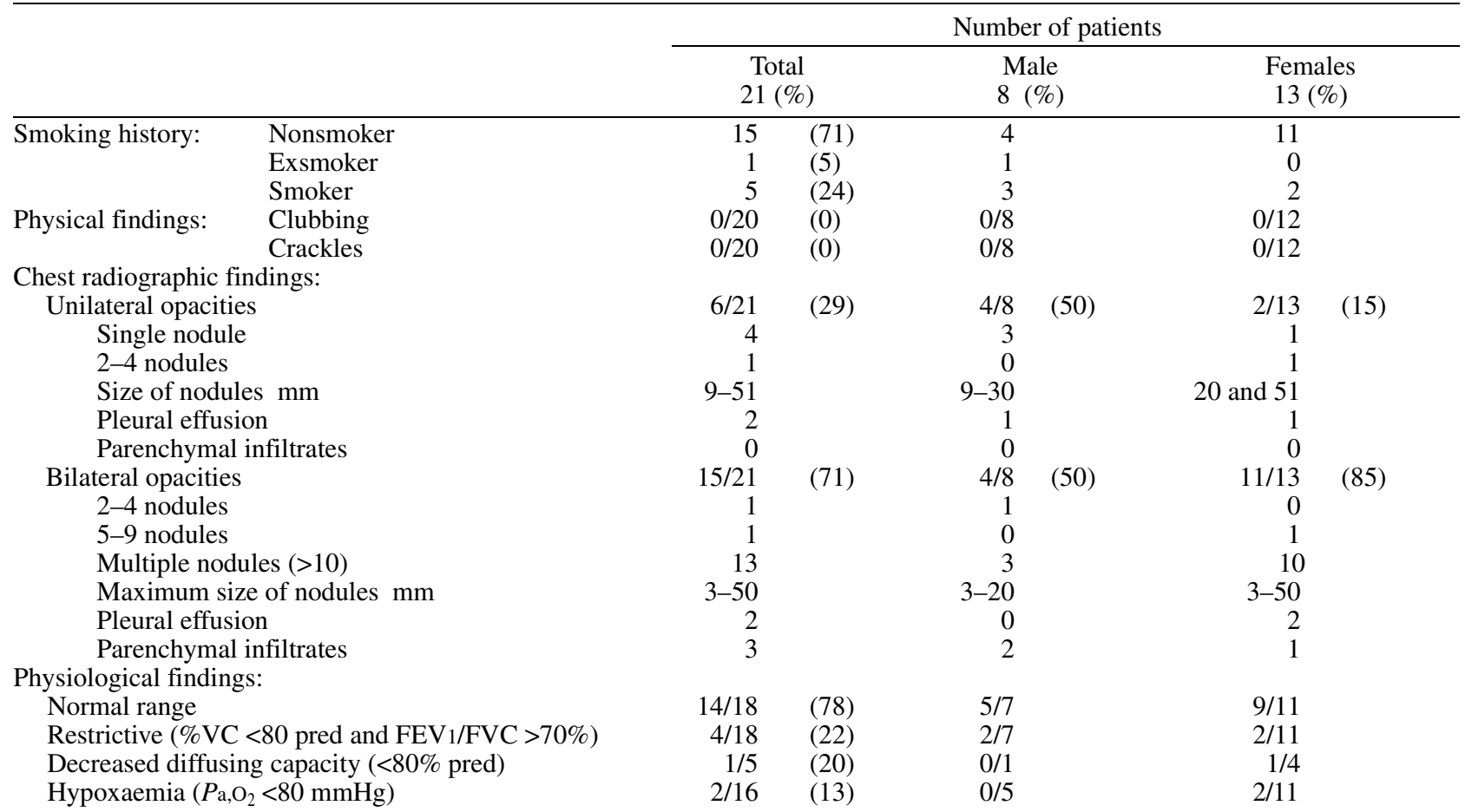

VC: vital capacity; FEV1: forced expiratory volume in one second; FVC: forced vital capacity; $P \mathrm{a}, \mathrm{O}_{2}$ : arterial oxygen tension. (1 $\mathrm{mmHg}=0.133 \mathrm{kPa})$

Table 3. - Findings at computed tomography of the chest in 18 patients with pulmonary epithelioid haemangioendothelioma

\begin{tabular}{lccc}
\hline & \multicolumn{3}{c}{ Number of patients } \\
\cline { 2 - 4 } & Total & Males & Females \\
& $18(\%)$ & $8(\%)$ & $10(\%)$ \\
\hline Unilateral opacities & $4 / 18(22)$ & $3 / 8(38)$ & $1 / 10(10)$ \\
Pleural effusion without & 1 & 1 & 0 \\
nodular opacities & & & \\
Single nodular opacity & 2 & 1 & 1 \\
Several nodular opacities & 1 & 1 & 0 \\
Ground glass opacities & 3 & 2 & 1 \\
Linear opacities & 2 & 2 & 0 \\
Bilateral opacities & $14 / 18(78)$ & $5 / 8(63)$ & $9 / 10(90)$ \\
5-9 nodular opacities & 1 & 0 & 1 \\
Multiple nodular opacities & 13 & 5 & 8 \\
Pleural effusion & 1 & 0 & 1 \\
Ground glass opacities & 5 & 1 & 4 \\
Linear opacities & 3 & 1 & 2 \\
Lymphadenopathy & $0 / 18(0)$ & $0 / 8$ & $0 / 10$ \\
\hline
\end{tabular}

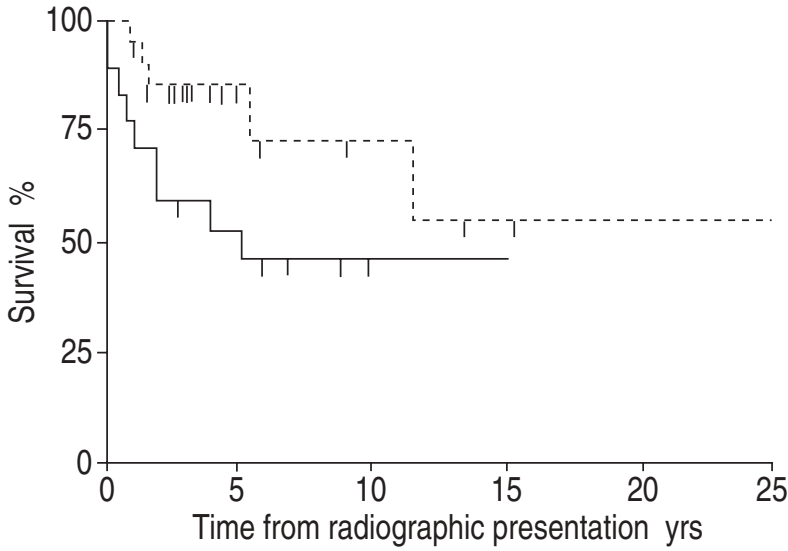

Fig. 1. - Kaplan-Meier plots of actuarial survival of the 17 patients (—) reported by DAIL et al. [2], from the initial radiographic presentation or biopsy documentation, versus the 21 patients (- - -) in the present study, from the onset of symptoms or the detection of abnormal chest radiographic findings (Kyoto Meeting, 1994). The difference in survival was statistically significant $(\mathrm{p}<0.05)$.

Table 4. - Clinical features of three pulmonary epithelioid haemangioendothelioma patients with partial spontaneous regression

\begin{tabular}{|c|c|c|c|c|}
\hline $\begin{array}{l}\text { Patient no./sex/age } \\
\text { at first examination }\end{array}$ & $\begin{array}{l}\text { Subjective } \\
\text { symptom }\end{array}$ & $\begin{array}{l}\text { Chest radiographic } \\
\text { findings }\end{array}$ & Method of diagnosis & Prognosis* \\
\hline$\overline{1 / F / 45[14]}$ & None $^{\dagger}$ & BMN & OLB at $45 \mathrm{yrs}$ & $\begin{array}{l}\text { Reduction of the largest pulmonary nodules from } \\
5 \text { to } 3 \mathrm{~mm} \text { during } 13 \mathrm{yrs} \text { and } 3 \text { months }\end{array}$ \\
\hline $2 / \mathrm{M} / 18[15]$ & None $^{\dagger}$ & $\mathrm{BMN}$ & OLB at 18 yrs & $\begin{array}{l}\text { Reduction of the largest pulmonary nodules from } \\
11 \text { to } 8 \mathrm{~mm} \text { during } 5 \mathrm{yrs} \text { and } 11 \text { months }\end{array}$ \\
\hline $3 / F / 48[16]$ & None ${ }^{\dagger}$ & $\mathrm{BMN}$ & OLB at 48 yrs & $\begin{array}{l}\text { Reduction of the largest pulmonary nodules from } \\
8 \text { to } 5 \mathrm{~mm} \text { during } 15 \mathrm{yrs} \text { and } 4 \text { months }\end{array}$ \\
\hline
\end{tabular}

F: female; M: male; BMN: bilateral multiple nodular lesions; OLB: open lung biopsy. *: The three patients [14-16] remained asymptomatic without therapy. ${ }^{\dagger}$ : All three patients were detected at systematic health examinations. 

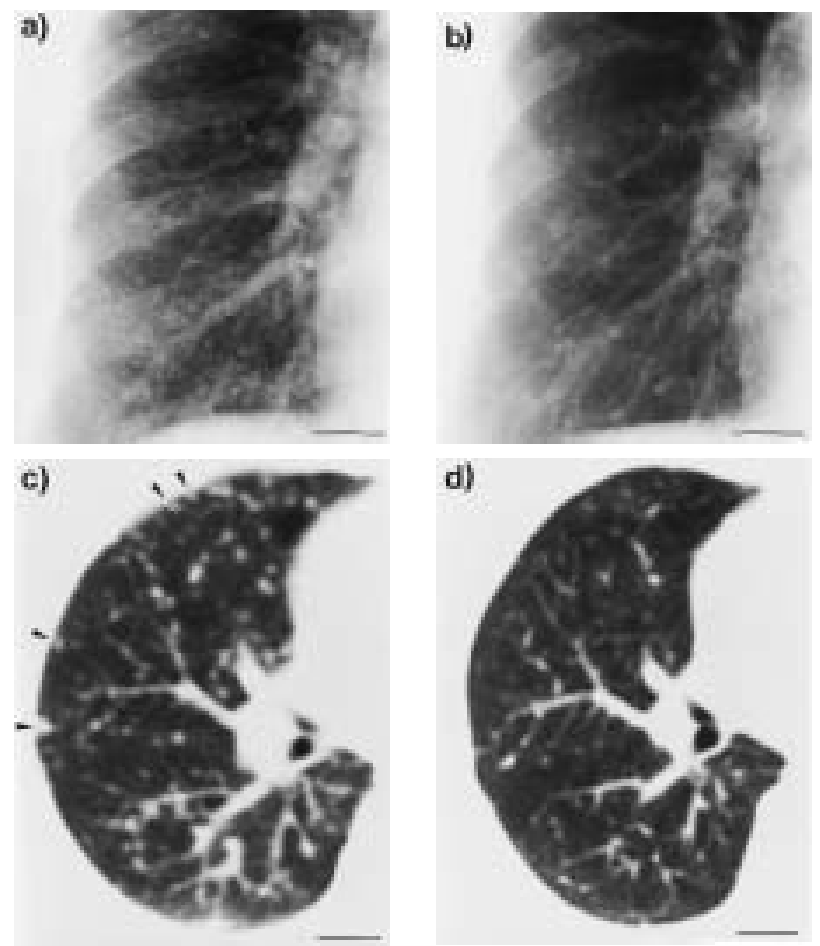

Fig. 2. - Radiological findings of the right middle and lower lung field in patient 1 (table 4), showing partial spontaneous regression. a) Chest radiograph before open lung biopsy, showing multiple bilateral nodular opacities with a maximum diameter of $5 \mathrm{~mm}$ (the biopsy specimen was taken from the left lower lobe in March 1981). b) Chest radiograph of the same area 13 yrs and 3 months later, showing partial spontaneous regression of bilateral pulmonary opacities. The largest nodular opacity was $3 \mathrm{~mm}$ in diameter. The patient was followed as an outpatient without treatment. c) Computed tomography (CT) scan of the chest in February 1981 before the open lung biopsy confirmed multiple nodular opacities (arrowheads) in the right lung field (corresponds to the chest radiograph in a). d) CT scan of the chest 12 yrs and 1 month later, confirmed partial regression of the opacities (corresponds to the chest radiograph in b). (Internal scale bars $=20 \mathrm{~mm}$ ).
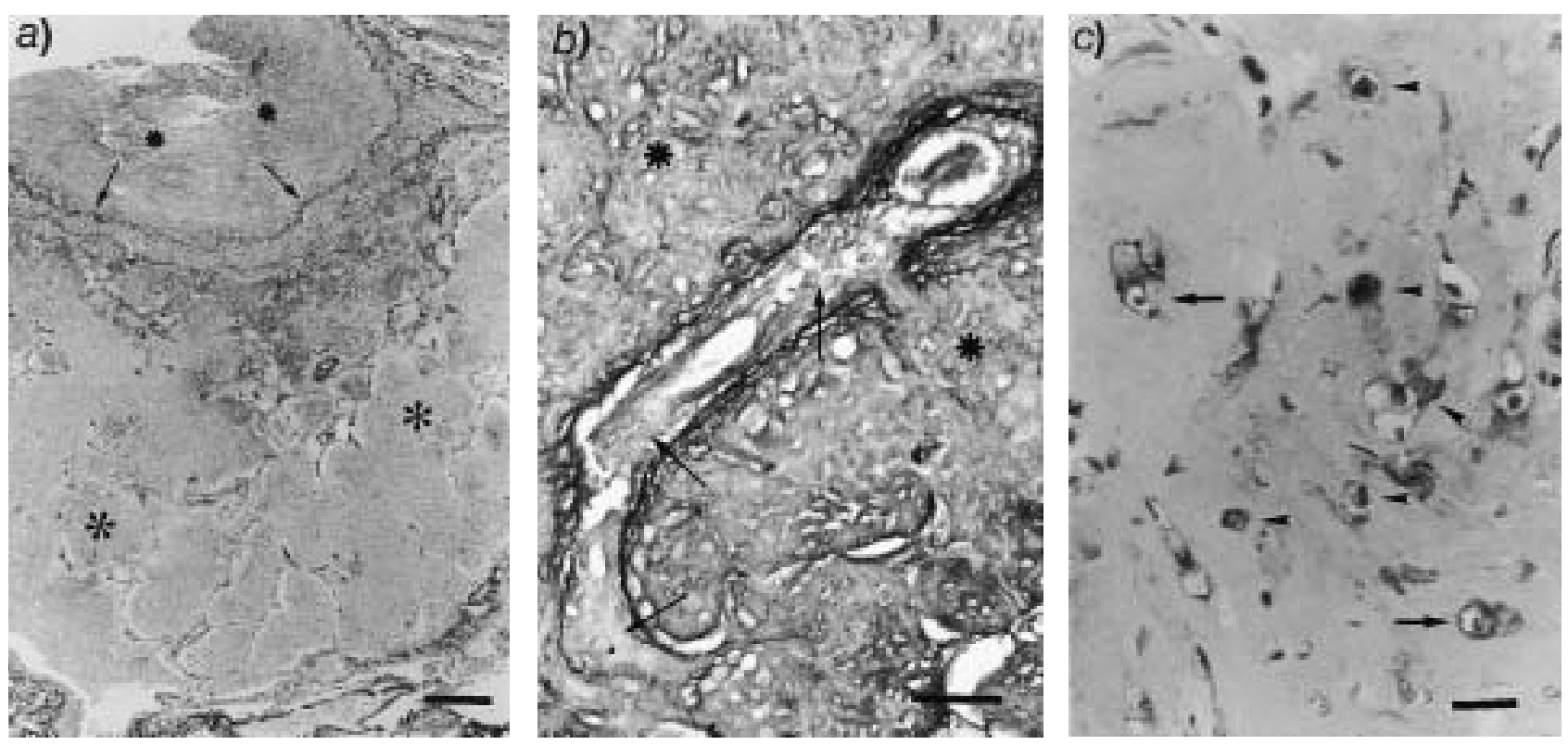

Fig. 3. - Pathological findings in the three pulmonary epithelioid haemangioendothelioma (PEH) patients who showed partial spontaneous regression (table 4). a) Nodular neoplastic lesion of PEH with hyalinous extracellular matrix showing infiltration in the visceral pleura (small asterisks) beyond the external elastic layer of the pleura (arrows), and in the subpleural alveolar regions (large asterisks) (patient 1 in table 4). (Weigert's elastic tissue staining; internal scale bar=200 $\mu$ m). b) Tumour cells of PEH infiltrate in the wall and lumen of a muscular pulmonary artery (arrows) and in the adjacent aleolar regions (asterisks) (patient 2 in table 4). (Weigert's elastic tissue stain; internal scale bar=100 $\mu \mathrm{m}$ ). c) Tumour cells of PEH are positive for the antibody against factor VIII-related antigen in their cytoplasm (arrowheads). Some tumour cells form vascular lumens, a few of which contain erythrocytes (arrows) (patient 2 in table 4). (Streptavidin-biotin complex method; internal scale bar $=20 \mu \mathrm{m})$. 

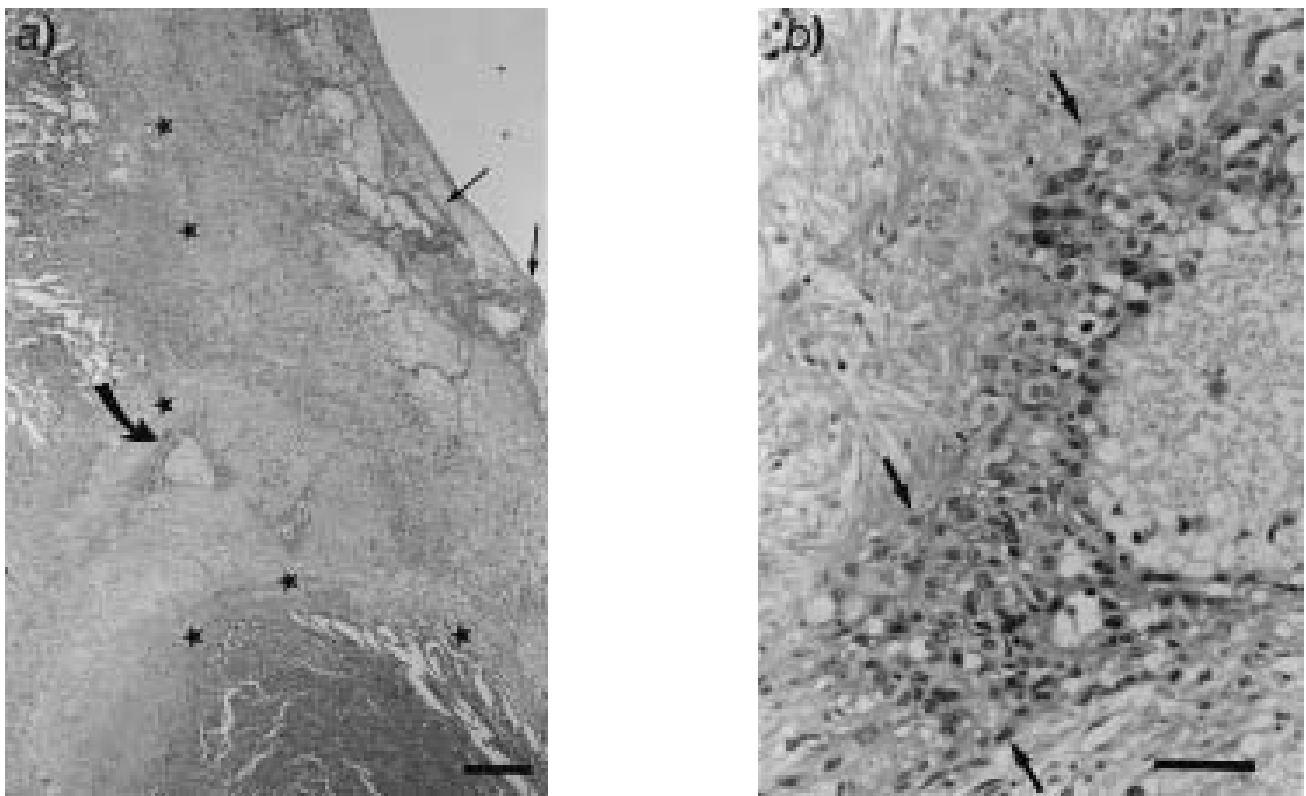

Fig. 4. - Fibrinofibrous pleuritis in patients with pulmonary epithelioid haemangioendothelioma. a) Surgically resected lung specimen showing fibrinous exudates (straight arrows) and neoplastic cells (curved arrow) outside the visceral pleura (asterisks). These findings were confirmed to be indicative for a worse clinical outcome in the present study. (Haematoxylin and eosin staining; internal scale bar=200 $\mu \mathrm{m}$ ). b) Higher magnification showing neoplastic cells (arrows) in the fibrotic lesion of fibrinofibrous pleuritis. (Haematoxylin and eosin staining; internal scale bar=40 $\mu m$ ).

stable and showed no changes in symptoms or chest radiographic findings over follow-up periods ranging from 5 months to 26 yrs and 8 months. The two remaining patients showed progression of $\mathrm{PEH}$ on the chest radiograph during the follow-up (range 1-20 months).

\section{Treatments and their effect on outcome}

Five patients with unilateral opacities underwent surgical resection. The three patients who had only a single nodule and underwent lobectomy are alive and well without recurrence at 3 yrs $(n=2)$ and 4 yrs $(n=1)$ after surgery. One patient who had several nodular opacities, which were removed by wedge resection, died with bilateral pleural effusion and ascites 11 months after surgery [22]. One patient who had unilateral pleural effusion and underwent pleuropneumonectomy, died at 7 months after surgery from an unknown cause. Of the 15 patients with bilateral $\mathrm{PEH}$, three underwent resectional surgery (right upper and middle bilobectomy [26], right middle lobectomy and bilateral partial resection, respectively). Five out of these 15 received chemotherapy, such as mitomycin $\mathrm{C}$, 5-fluorouracil, cyclophosphamide, vincristine and teqafur. The chemotherapy had no apparent beneficial effects. Among the three surgical cases cited above, one died 19 months after right upper and middle bilobectomy [26]. The other two patients were alive at 28 months and at 4 yrs, respectively. Among the five patients who received chemotherapy, two died 5 months [17], and 11 yrs and 7 months after the first examination, respectively, owing to progression of their disease. The other two patients are alive at 29 months and 22 months, respectively, after the termination of chemotherapy (cyclophosphamide for 1 week and cisplatin for 2 months) (see also Overall prognosis section).

\section{Analysis of clinical prognostic factors}

Among the clinical and radiographic findings, pleural effusion noted on chest radiography was a statistically significant prognostic factor. Symptomatic patients showed a trend towards a worse prognosis, but this was not significant. Six out of seven patients $(86 \%)$ without subjective symptoms at their first examination remain alive, while only one out of three patients (33\%) with subjective symptoms is alive at $5 \mathrm{yrs}$ after the first examination $(\mathrm{p}=0.15)$. Pleural effusion was noted in four patients at the time of their first examination. Only one out of three patients with pleural effusion on chest radiography at the time of the first examination survived for 1 year, while all 16 patients who had no pleural effusion survived for $>1 \mathrm{yr}(\mathrm{p}<0.05)$ (table 5).

\section{Correlation between histopathological findings and prog- nosis}

Among the histological findings studied, fibrinofibrous pleuritic lesions with extrapleural proliferation of tumour cells (fig. 4) and the presence of spindle tumour cells were features of worse prognosis (table 6). Indeed, among the $21 \mathrm{PEH}$ patients, three showed diffuse fibrinofibrous pleuritis up to $2 \mathrm{~mm}$ in thickness. Round neoplastic cells were observed in the fibrotic lesions on the visceral pleura, while fibrinous exudates were observed on the fibrotic lesions of pleuritis (fig. 4). Both patients with fibrinofibrous pleuritic features and extrapleural proliferation of tumour cells died within 2 yrs of diagnosis, while only one out of the 14 patients $(7 \%)$ without such findings died within 2 yrs of diagnosis $(\mathrm{p}<0.05)$ (table 6, fig. 4). Spindle tumour cells were observed in 13 out of the $21 \mathrm{PEH}$ patients. While all three patients without spindle tumour cells are alive at 12 yrs after the pathological diagnosis, all four patients with spindle tumour cells died during the same period $(\mathrm{p}<0.05)$ 
(table 6). However, intravascular invasion $[14,15]$ and invasion of the visceral pleura by tumour cells without fibrinous pleuritis [14] were observed in the two PEH patients with spontaneous partial regression (fig. 3). The significance of these findings in only two cases remains elusive.

Mitotic figures in tumour cells were rare. Only one patient showed at least one mitotic figure among 10 highpower fields of the tumour in the surgically resected lung specimen. The patient died of PEH with skin and bone metastases 19 months after the surgery [26].

Table 6. - Pulmonary histopathological findings of 21 patients with pulmonary epithelioid haemangioendothelioma (PEH)

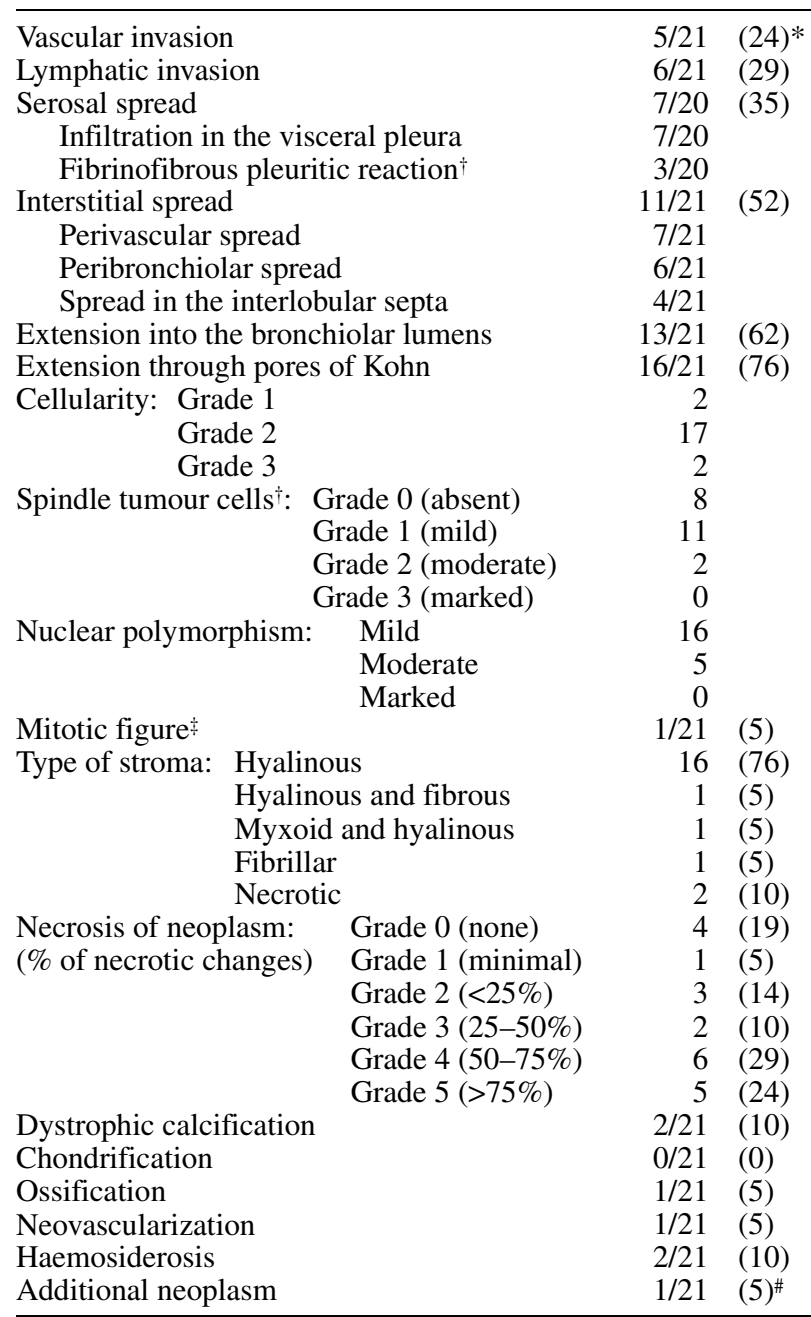

Data are presented as numbers of patients with percentages in parenthesis. *: pulmonary artery 3 , pulmonary artery and vein 1 , pulmonary vein $1 .{ }^{\dagger}$ : Among 18 patients with diagnostic thoracotomy, both patients with histological fibrinofibrous pleuritis died within 2 yrs, while only one out of 14 patients without fibrinofibrous pleuritis died in the same period $(\mathrm{p}<0.05)$. Among 20 patients with diagnostic lung biopsy or surgery, all three patients without spindle tumour cells were alive 12 yrs after the pathological diagnosis, while all four patients with spindle tumour cells died during the same period $(\mathrm{p}<0.05)$. The other histological findings were not demonstrated to be statistically significant prognostic factors. $\$$ : Only one patient who underwent surgical lung resection showed a mitotic figure among 10 high-power fields. \#: One patient showed growth of bronchoalveolar cell carcinoma around nodular lesions of PEH.

\section{Discussion}

The present study is the largest so far devoted to $\mathrm{PEH}$, a rare pulmonary tumour. In addition, it is the first report to document partial spontaneous regression of $\mathrm{PEH}$, as seen in three (14\%) of the 21 patients.

The majority of patients with PEH were females (13, i.e. $62 \%$ in the present study; $80 \%$ in the report by $\mathrm{D}_{\text {All }}$ et al. [2]). The age of the patients at the first examination ranged 7-76 yrs, with the youngest patient being reported by Rock et al. [27] and the oldest by CARTER et al. [28]. The usual age range for diagnosis is $20-60$ yrs (15 pat-ients, i.e. $71 \%$ in the present study; $85 \%$ in [2]). Many PEH patients are asymptomatic at the time of diagnosis and are detected by abnormal chest radiography $(76 \%$ in the present study; $50 \%$ in [2]). There is no characteristic clinical or biological marker for PEH. Chest pain, cough and sputum are common as are nonspecific symptoms. Two patients presented with alveolar haemorrhage $[28,29]$ and one with rapidly deteriorating pulmonary hypertension [30].

Radiographically, bilateral multiple nodular opacities are the most common presentation $(n=13$, i.e. $62 \%$ in the present study; $65 \%$ in [2]). The nodular opacities are usually $<2 \mathrm{~cm}$ in diameter [9, 13]. PEH occasionally develops as a solitary lung nodule, measuring up to $5 \mathrm{~cm}$. The frequency of this presentation lies between 10\% [2] and 19\% (present study) of cases.

Macroscopically in PEH, there are solitary or multiple pulmonary nodules measuring several millimetres, up to 5 $\mathrm{cm}$ in diameter. Their consistency is rubbery or cartilagelike. The cut surface is grey-white to yellow-brown, with semitranslucency or nontranslucency. Calcifications are rarely seen.

Histologically, the periphery of the neoplasm is hypercellular, while the centre is hypocellular with coagulative necrosis, hyalinization, calcification or even ossification $[2,9,12,13]$ (fig. 3a, table 6). The tumour cells are round with an abundant cytoplasm, while the nucleus is round or oval, with low-grade atypia, evenly distributed chromatin and scarce mitotic figures $[2,12]$. Spindle-shaped tumour cells are occasionally seen. The cell growth may form lumens of various size, which may contain red blood cells $[10,13]$ (fig. 3c). At the periphery of the nodule, tumour cells extend to adjacent alveoli through the pores of Kohn, in the form of a micropolypoid growth into the lumen of respiratory and membranous bronchioles $[2,9]$. However, the alveolar elastic framework is essentially preserved, as demonstrated on elastic tissue stains [2, 7, 13] (figs. 3a and $b$ ). The neoplastic tissues may invade the walls and lumens of small pulmonary arteries, veins and lymphatics. Inflammatory cellular infiltrate, congestion in the adjacent lung parenchyma and fibrin thrombosis are usually not seen $[2,9,13]$.

The majority of PEH patients reported to date $[2,5,7$, 8], and the 21 patients described herein, had a chronic clinical course. The longest survivor of PEH was a female patient reported by MIETTINen et al. [31]. The patient un-derwent 13 operations, including 11 thoracotomies bet-ween the age of 17-41 yrs. The patient received neither radiation nor cytostatic therapy and died from pneumonia 24 yrs after the onset of the disease [32]. Through the present study, the female PEH patient reported by Teo et al. [21] was confirmed to be alive and stable. The patient has 
received no specific therapy for the 30 yrs that have elapsed since the first detection of bilateral multiple nodular opacities.

The Kaplan-Meier survival plot of the $21 \mathrm{PEH}$ patients reported in this study was significantly better than that of $17 \mathrm{PEH}$ patients reported by DAll et al. [2] (fig. 1). However, the number of asymptomatic patients in this report was greater (16/21 patients, $76 \%)$ than in the report by $\mathrm{D}_{\text {All }}$ et al. [2] (7/16 patients, 44\%). Dall et al. [2] reported that 11 out of 17 PEH patients with follow-up information were known to have died of their disease between 1-15 yrs after diagnosis [13]. They pointed to some ominous prognostic factors for PEH [2] and identified the presence of respiratory symptoms at presentation, extensive lymphangitic spread, pleural invasion, extensive intravascular, endobronchial or interstitial tumour spread, hepatic metastases and peripheral lymphadenopathy [2, 13], as factors of unfavourable outcome. In addition, in patients with epithelioid haemagioendothelioma of soft tissues, the presence of spindle cells in the tumour was indicated as a worse prognostic factor $[10,13]$. In the present study, pleural effusion on chest radiography, fibrinofibrous pleuritis with extrapleural proliferation of tumour cells and spindle tumour cells at histology were significant unfavourable prognostic factors. However, it should be pointed out that two patients (cases 1 and 2 in table 4) showing proliferation of tumour cells in the visceral pleura, but who had no fibrinofibrous pleuritis, showed spontaneous partial regression (table 4, figs. 2 and 3). Patients with hilar metastasis or liver involvement were reported to have a worse prognosis, with an average survival of 2.2 yrs [32]. However, two patients (cases 1 and 2 in table 4 ) had hepatic involvement at CT examination of the abdomen (not confirmed histopathologically) at the time of diagnosis $[14,15]$. Clearly, the prognostic significance of hepatic involvement in PEH requires further study.

Dissemination of PEH can occur through blood vessels and lymphatics, and within the pleural cavity. The spread through the airspaces of the lung is continuous [2, 9]. Although rare, distant metastases of the liver, skin, kidney, spleen and retroperitoneum can occur, presumably via the bloodstream $[2,26,31]$. In contrast, three patients were asymptomatic and had multiple bilateral pulmonary nodules. They demonstrated similar histopathological findings in the OLB specimen (table 4, figs. 2 and 3) [14-16]. They were followed up with no specific therapy, based on the recommendation by $\mathrm{D}_{\mathrm{AlL}}$ et al. [2], and there was no relapse. This tends to confirm the adequacy of the "no therapy" attitude, especially in asymptomatic patients.

Regarding therapy in $\mathrm{PEH}$, surgical resection seems to be the treatment of choice, whenever the PEH lesion is solitary or the number of lesions is limited $[9,13,31]$. All three PEH patients with a solitary lesion of PEH in this study are alive after surgical resection, with a mean follow-up of 44 months (see Overall prognosis section). No chemotherapy has demonstrated efficiency in PEH [9]. Antineoplastic chemotherapy was used in five patients in the present study; however, none of the drugs or regimens tried proved to be effective, as also reported by Dall et al. [2]. The five patients treated with mitomycin C, 5-fluorouracil, cyclophosphamide, vincristine, tegafur or cisplatin received no beneficial effect. Radiation is not effective for PEH $[9,13]$. As stated above, the overall prognosis of PEH in this study was better than that in the study by DAll et al.
[2] (fig. 1). To what extent this is related to the "no therapy" approach adopted in the management of asymptomatic patients is unclear. This approach was originally recommended in the report of DAlL et al. [2], to avoid adverse effects of ineffective chemotherapeutic agents, and should be discussed in patients with PEH. Recently, RoUdiER-Pujol et al. [33] reported a young woman with epithelioid haemangioendothelioma involving the skin, bone, lung and liver, who demonstrated partial remission after 1 $\mathrm{yr}$ of treatment with $\alpha-2 \mathrm{~A}$ interferon. In addition to surgery for localized lesions of epithelioid haemangioendothelioma, they suggested therapy using interferon, interleukin2 and retinoids. Ideally, randomized studies would be useful to confirm or refute these results in PEH.

We recommend making regular check-ups on PEH patients, every 3-6 months in patients with asymptomatic bilateral pulmonary nodules as well as after curative surgical resection. However, the possible merit of this approach is unknown. For instance, patient 3 (table 4) had no chest radiograph for $10 \mathrm{yrs}$ after the report of the case history [16]. One male patient had mild dyspnoea on exertion and bilateral multiple pulmonary nodules on the chest radiograph detected during a health examination. The histological diagnosis of PEH was made by transbronchial and liver biopsy at the age of $14 \mathrm{yrs}$. After a period of $11 \mathrm{yrs}$ without therapy, the patient developed bilateral pleural effusions. The patient died of progressive PEH 6 months later. Post mortem examination confirmed PEH.

One patient in the present study showed bronchoalveolar carcinoma in the pulmonary parenchyma adjacent to the nodular lesions of PEH, as was also the case in one patient reported by $\mathrm{D}_{\text {AlL }}$ et al. $[1,2]$. PEH was originally reported as IVBAT $[1,2]$. This term was useful originally, in order to emphasize the characteristic growth pattern of the tumour, namely intravascular intrabronchiolar and intra-alveolar, along with a sclerosing collagenous matrix. These features made diagnosis possible without the aid of immunohistology or electron microscopy [14]. However, IBVAT or PEH has been demonstrated to derive from endothelial cells, according to the positive immunohistology for endothelial cell markers, such as factor VIII-related antigen, Ulex and CD34, and also by the presence of Weibel-Palade bodies in the cytoplasm of tumour cells on electron microscopy [2-13]. The association with bronchoalveolar carcinoma was considered incidental, and its frequency among PEH patients is low (about 5\%) [2,9]. The term PEH should be used to indicate that IVBAT is a member of the family of epithelioid haemangioendotheliomas [9, 13]. This will help in sharing advances in epithelioid haemangioendotheliomas of other organs, especially for the application of effective therapies [33]. The use of the term IVBAT should be abandoned as it applied to the lung only.

In conclusion, 21 patients with pulmonary epithelioid haemangioendothelioma have been described in detail. Three of them exhibited spontaneous partial regression, which is a rare event. Pleural effusion, fibrinofibrous pleuritis with extrapleural proliferation of tumour cells at histology and the presence of spindle tumour cells were features of worse prognosis. Slow progression or growth for extended periods and spontaneous regression may occur, especially in asymptomatic patients, even though they may have bilateral lesions. Careful follow-up is warranted and effective therapies are awaited. 
Acknowledgements: This report is a joint study of the following 20 hospitals in Japan, Korea, Taiwan and Singapore: Ooita Prefectural Hospital (T. Taguchi at Nagasaki University), National Okinawa Hospital (K.Genka), Ooita Almeida Hospital (T. Mieno), Fukuoka University Hospital (K. Ando and T. Shirakusa), Yamanashi University Hospital (K. Nishikawa), Kumamoto Central Hospital (N. Fujino), Shimonoseki City Hospital (A. Tanimura, M. Ekimura and M. Akao), Tokushima Prefectural Central Hospital (H. Yanagawa), National Cancer Center Hospital East (K. Takahashi and T. Kodama), Japanese Red Cross Medical Center (I. Tanaka and T. Takemura), Keio University Hospital (T. Urano and M. Kanazawa), Mie University Hospital (H. Ibata), Ohgaki Municipal Hospital (J. Sindoh), Kurashiki Daiichi Hospital (H. Yoneyama), Kansai Denryoku Hospital (K. Itoi), Kyoto City Hospital (K. Hamamoto and E. Kim), Chest Disease Research Institute Hospital of Kyoto University (J. Chihara at Akita University Hospital and M. Miyake at Kitano Hospital in Osaka), Seoul National University Hospital in Seoul (C.G. Yoo, C.J. Kim and J.W. Seo), Chang Gung Memorial Hospital in Taipei (Y.H. Tsai) and Tan Tock Seng Hospital in Singapore (G. Chiang). The authors thank S. Saiki, M. Kikui and J. Ikezoe, who attended the Meeting on PEH (February 25, 1994, Kyoto) and discussed the patients of the present study, Y. Fujiyoshi, T. Yokoi, M. Kanaoka, M. Shigematsu, K. Minowa and T. Kanematsu for their collaboration, and H. Koyama for his contribution to statistical methods. The authors thank Banyu Pharmaceutical Co. Ltd for supporting our meeting and A. Johnson for linguistic corrections.

\section{References}

1. Dail DH, Liebow AA. Intravascular bronchioloalveolar tumor. Am J Pathol 1975; 78: 6a-7a.

2. Dail DH, Liebow AA, Gmelich JT, et al. Intravascular, bronchiolar, and alveolar tumor of the lung (IVBAT): an analysis of twenty cases of a peculiar sclerosing endothelial tumor. Cancer 1983; 51: 452-464.

3. Corrin B, Manners B, Millard M, Weaver L. Histogenesis of the so-called "intravascular bronchioloalveolar tumor". J Pathol 1979; 123: 163-167.

4. Azumi N, Churg A. Intravascular and sclerosing bronchioloalveolar tumor: a pulmonary sarcoma of probable vascular origin. Am J Surg Pathol 1981; 5: 587-596.

5. Weldon-Linne CM, Victor TA, Christ ML, Fry WA. Angiogenic nature of the "intravascular bronchioloalveolar tumor" of the lung: an electron microscopic study. Arch Pathol Lab Med 1981; 105: 174-179.

6. Weldon-Linne CM, Victor TA, Christ MA. Immunohistochemical identification of factor VIII-related antigen in the intravascular bronchiolalveolar tumor of the lung. Arch Pathol Lab Med 1981; 105: 628-629.

7. Bhagavan BS, Murthy MSN, Dorfman HD, Eggleston JC. Intravascular bronchioloalveolar tumor (IVBAT): a low-grade sclerosing epithelioid angiosarcoma of lung. Am J Surg Pathol 1982; 6: 41-52.

8. Pilotti S, Rilke F, Lombardi L, Pastorino U. Immunohistochemistry and elecron microscopy on intravascular bronchioloalvelar tumor of the lung. Tumori 1983; 69: 283-292.

9. Dail DH. Epithelioid hemangioendothelioma. In: Dail DH, Hammar SP, eds. Pulmonary Pathology, 2nd edn. New York, Springer, 1994; pp. 1406-1414.

10. Weiss SW, Enzinger FM. Epithelioid hemangioendothelioma: a vascular tumor often mistaken for a carcinoma. Cancer 1982; 50: 970-981.

11. Eggleston JC. The intravascular bronchioloalveolar tumor and the sclerosing hemangioma of the lung: misnomers of pulmonary neoplasia. Semin Diagn Pathol 1985; 2: 270-280.

12. Colby TV, Koss MN, Travis WD. Epithelioid hemangioendothelioma. In: Atlas of Tumor Pathology. Tumors of the Lower Respiratory Tract. Washington, DC, Armed Forces Institute of Pathology, 1995; pp. 363-370.

13. Weiss SW, Ishak KG, Dail DH, Sweet DE, Enzinger FM. Epithelioid hemangioendothelioma and related lesions. Sem Diag Pathol 1986; 3: 259-287.

14. Chihara J, Kitaichi M, Oshima S, Izumi T, Nakayashiki $\mathrm{H}$, Kobara Y. A case of intravascular bronchioloalveolar tumor (IVBAT) with multiple small nodular shadows on chest X-ray detected in mass survey examination.
Nippon Kyobu Shikkan Gakkai Zasshi (Jpn J Thorac Dis) 1983; 21: 95-99 (in Japanese, with English Abstract).

15. Miyake M, Ito M, Taki T, et al. A case of IVBAT (intravascular bronchioloalveolar tumour). Nippon Kyobu Shikkan Gakkai Zasshi (Jpn J Thorac Dis) 1986; 24: 74-78 (in Japanese, with English Abstract).

16. Genka K, Nagamine N, Ishikawa K, Kuniyoshi M, Miyasato K, Nohara Y. A case of intravascular bronchioloalveolar tumor. Kokyuu (Respir Res) 1983; 2: 129-133 (in Japanese, with English Abstract).

17. Taguchi T, Tsuji K, Matsuo K, Takebayashi S, Kawahara $\mathrm{K}$, Hadama T. Intravascular bronchioloalveolar tumor: report of an autopsy case and review of literature. Acta Pathol Jpn 1985; 35: 631-642.

18. Leader M, Collins M, Patel J, Henry K. Staining for factor VIII-related antigen and Ulex europaeus agglutinin I (UEA-I) in 230 tumours: an assessment of their specificity for angiosarcoma and Kaposi's sarcoma. Histopathology 1986; 10: 1153-1162.

19. Kanematsu T, Kitaichi M, Nishimura K, Nagai S, Izumi T. Clubbing of fingers and smooth-muscle proliferation in fibrotic changes in the lung in patients with idiopathic pulmonary fibrosis. Chest 1994; 105: 339-342.

20. Dawson-Saunders B, Trapp RG. Basic and Clinical Biostatistics, 2nd edn. London, Prentice-Hall, 1994; pp. 189209.

21. Teo SK, Chiang SC, Tan KK. Intravascular bronchioloalveolar tumor: a 20-year survival. Med J Aust 1985; 142: 220-222.

22. Watanabe Y, Inuzuka S, Kasahara D, et al. A case of intravascular bronchioloalveolar tumor (IVBAT) with peritoneal dissemination. Haigan (Lung Cancer) 1987; 27: 79-85 (in Japanese, with English Abstract).

23. Shirakusa T, Yoshida M, Tsutsui M, et al. Advanced intravascular bronchioloalveolar tumour and review of reports in Japan. Respir Med 1989; 85: 127-132.

24. Kim E, Takasu K. A case of IBVAT. Byoin Byori (Hosp Pathol) 1990; 8: 2 (in Japanese).

25. Shinmachi A, Shindou J, Horiba M, Hara M, Kato M, Yokoi T. A case report of intravascular bronchioloalveolar tumor (IVBAT) diagnosed by an OLB. Nippon Kyobu Shikkan Gakkai Zasshi (Jpn J Thorac Dis) 1993; 31: 1285-1290 (in Japanese, with English Abstract).

26. Yanagawa H, Hashimoto Y, Bando H, Takishita Y, Nagano T. Intravascular bronchioloalveolar tumor with skin metastases. Chest 1994; 105: 1882-1884.

27. Rock MJ, Kaufman RA, Lobe TE, Hensley SD, Moss ML. Epithlioid hemangioendothelioma of the lung (intravascular bronchioloalveolar tumor) in a young girl. Pediatr Pulm 1991; 11: 181-186.

28. Carter EJ, Bradburne RM, Jhung JW, Ettensohn DB. Alveolar hemorrhage with epithelioid hemangioendo-thelioma: a previously unreported manifestation of a rare tumor. Am Rev Respir Dis 1990; 142: 700-701.

29. Briens E, Caulet-Maugendre S, Desrues B, et al. Alveolar haemorrhage revealing epithelioid haemangioendothelioma. Respir Med 1997; 91: 111-114.

30. Yi ES, Auger WR, Friedman PJ, Morris TA, Shin SS. Intravascular bronchioloalveolar tumor of the lung presenting as pulmonary thromboembolic disease and pulmonary hypertension. Arch Pathol Lab Med 1995; 119: 255-260.

31. Miettinen M, Collan Y, Halttunen P, Maamies T, Vilkko P. Intravascular brochioloalveolar tumor. Cancer 1987; 24712475.

32. Ross GJ, Violi L, Friedman AC, Edmonds RR, Unger E. Intravascular bronchioloalveolar tumor: CT and pathologic correlation. J Comput Assist Tomogr 1989; 13: 240243.

33. Roudier-Pujol C, Enjolras O, Lacronique J, et al. Multicentric epithelioid hemangioendothelioma in partial remission with interferon treatment. Ann Dermatol Venereol 1994; 121: 898-904 (in French, with English Abstract). 